\title{
REVISTAMARACANAN
}

Artigo

\section{Entre a repressão policial e o saber médico: 0 controle social da loucura no Espírito Santo entre o fim do século XIX e os anos 1950}

\author{
Between police repression and medical knowledge: The social control of \\ madness in the Holy Spirit between 1950 and 1950
}

Júlia Freire Perini*

Universidade Federal do Espírito Santo, Brasil

Marcelo Durão Rodrigues da Cunha**

Universidade Federal do Espírito Santo, Brasil

Recebido: 30 ago. 2018.

Aprovado: 06 nov. 2018.

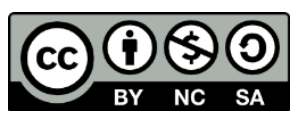

\footnotetext{
Este artigo é um dos desdobramentos de pesquisa financiada pela CAPES.

* Doutoranda do Programa de Pós-Graduação em História da Universidade Federal do Espírito Santo (UFES), sob orientação da Prof. a Dr. a Juçara Luzia Leite. Mestre em História pela UFES e graduada em História pela Universidade Federal de Ouro Preto. (juliafreireperini@gmail.com)

ORCID iD:. https://orcid.org/0000-0002-6952-4860.

CV Lattes: http://lattes.cnpq.br/9305916400288656.

** Professor do ensino básico, técnico e tecnológico do Instituto Federal do Espírito Santo, Campus Itapina. Doutor, Mestre e graduado em História pela Universidade Federal do Espírito Santo. (marceloduraocunha@gmail.com)

ORCID iD: http://orcid.org/0000-0001-6585-6836.

CV Lattes: http://lattes.cnpq.br/3416308333458306.
} 


\title{
Resumo
}

O presente artigo visa oferecer um panorama histórico do que foi o trato com o problema social da loucura entre o final do século XIX e os anos cinquenta do século XX no estado do Espírito Santo. Pautando-nos em uma análise do desenvolvimento de instituições e de saberes médicos em âmbito local, buscaremos compreender as principais características assumidas pela preocupação com o lugar do louco na sociedade capixaba ao longo do período em questão. Baseando-nos na crítica foucaultiana dos jogos de exclusão operados pelo saber científico na modernidade, sustentaremos a hipótese de que a institucionalização do trato com a loucura no Espírito Santo representou muito mais a ressignificação de antigas práticas repressivas e policialescas de exclusão do louco do corpo social local do que propriamente a sua superação. A fim de comprovar a hipótese em questão, analisaremos livros de entrada, prontuários e algumas entrevistas de funcionários daquela que seria a principal instituição responsável por modernizar e por superar o atraso em relação ao tratamento dos loucos nos anos 1950 em nosso estado: o Hospital Adauto Botelho.

Palavras-chave: História da Loucura. Espírito Santo. Adauto Botelho.

\begin{abstract}
This article offers a historical overview of the way by which the state of Espírito Santo dealt with the matter of madness as a social problem from the end of the nineteenth century until the 1950s. By targeting the development of medical knowledge and its institutions in the local sphere, we will try to understand the main characteristics assumed by the treatment of mental illness - and the place occupied by crazy individuals - in Espírito Santo's society during the referred period. By basing our analysis on Foucault's critics of the so-called exclusion games brought about by scientific kwowledge in modern times, it will be sustained that the institutionalization of the medical treatment of mental illness in Espírito Santo did not serve to overcome its old repressive and police practices but to intensify a process of exclusion of insane individuals which took place in that society at least since the last part of the nineteenth century. In order to prove that hypothesis, we will analyse entry books, medical records and interviews granted by some employees of Audauto Botelho Hospital: the main institution responsible of turning the treatment of madness in Espírito Santo into a modern medical enterprise during the 1950 s.
\end{abstract}

Keywords: History of madness. Espírito Santo. Adauto Botelho. 


\section{Introdução}

Um olhar sobre a historiografia especializada atesta que no estado do Espírito Santo a loucura foi administrada pelo poder público de modo ligeiramente diferente em relação aos grandes centros urbanos brasileiros no fim do século XIX e na primeira metade do século XX.

Segundo Alexander Jabert, por exemplo, apesar de o saber psiquiátrico ter se consolidado no Brasil ao longo do século passado, esse processo não ocorreu de maneira homogênea no país. O modo de organização dos estados no início da República permitiu maior autonomia a cada unidade federativa na forma de administrar as questões ligadas à saúde da população. Desse modo, o governo no âmbito nacional administrava diretamente o problema social da loucura principalmente na capital, deixando a cargo das administrações locais - como no caso do Espírito Santo - o trato com a referida mazela. ${ }^{1}$

Uma maneira de perceber essa diferença ocorre quando nos debruçamos sobre a história da criação dos saberes e das instituições especializadas na questão da loucura no Brasil oitocentista e na primeira metade do século $\mathrm{XX}$.

O primeiro hospício do Brasil foi criado em 1841 - se transformado subsequentemente em hospital público, em 1852, originando o Hospício Dom Pedro II. Posteriormente, foram inaugurados sanatórios em Recife no ano de 1861, em Salvador em 1874 e em Porto Alegre no fim do século XIX. ${ }^{2}$ Apenas cerca de um século depois, em 1944, é que a capital do Espírito Santo construiria o seu primeiro hospital voltado para o atendimento de doentes mentais: o Hospício de Alienados localizado na Ilha da Pólvora. Contudo, no que diz respeito à efetiva aplicação dos ditames médicos que vigoravam no período, esse processo de modernização do trato com a doença mental se completaria em território espírito-santense apenas no ano de 1954, com a inauguração do Hospital Colônia Adauto Botelho, no município de Cariacica.

Atestada essa diferença, poderíamos nos perguntar, portanto: quais medidas eram tomadas a respeito do problema social da loucura no Espírito Santo antes do advento das referidas instituições? Teria esse processo de institucionalização do saber psiquiátrico representado, de fato, uma ruptura em relação a antigas práticas de trato com a loucura no estado?

Uma resposta a essas perguntas requer uma análise preambular da história da relação estabelecida entre o poder público e a questão da doença mental na sociedade capixaba. Esse breve arrazoado histórico-genealógico é o que permitirá que demonstremos a hipótese central

\footnotetext{
1 JABERT, Alexander. Formas de administração da loucura na Primeira República: o caso do estado do Espírito Santo. História, Ciências, Saúde - Manguinhos, v. 12, n. 3, p. 693-716, set./dez. 2005, p. 695.

${ }^{2}$ Sobre o tema, ver os seguintes trabalhos: CUNHA, M. C. P. da. O espelho do mundo: Juquery, a história de um asilo. Rio de Janeiro: Paz e Terra. 1986; ENGEL, M. G. Psiquiatria e Feminilidade. In: DEL PRIORI, Mary (org.). História das mulheres no Brasil. São Paulo: Contexto, 1997, v. 1, p. 322-361; Oda, A. M. G. Raimundo; DALGALARRONDO, P. Histórias das primeiras instituições para alienados no Brasil. História, Ciências, Saúde - Manguinhos, v. 12, 983-1010, 2005; TEIXEIRA, L. A.; PIMENTA, T. S.; HOCHMAN, G. (orgs.). História da Saúde no Brasil. São Paulo: Hucitec, 2018.
} 
sustentada no presente artigo, qual seja, a de que a institucionalização do trato com a loucura no Espírito Santo - que teve como ápice, sobretudo, a construção do Hospital Colônia Adauto Botelho - representou muito mais a ressignificação de antigas práticas repressivas e policialescas de exclusão do louco do corpo social do que propriamente a sua superação.

Analisando o caso capixaba a partir daquilo que Michel Foucault interpretou como os "jogos de exclusão" característicos do advento da ciência psiquiátrica na modernidade, ${ }^{3}$ buscaremos compreender como na realidade capixaba esse tipo de discurso foi capaz de legitimar o controle dos corpos e de interditar aqueles indivíduos tidos como indesejáveis aos olhos da sociedade local. Os contornos desse processo e o seu desdobramento à luz das categorias foucaultianas em questão ficarão claros ao longo das páginas seguintes.

\section{Uma analítica da exclusão dos corpos: Foucault e a história da loucura}

No livro História da loucura na idade clássica, Foucault tinha o objetivo de estudar aquilo que ele concebia como uma espécie de estrutura de exclusão dos corpos, isto é, a compreensão de como operariam as tecnologias de exclusão e sua lógica interna ao longo da história ocidental. Para isso, ele propunha como tópico de estudo, como exemplo de exclusão, a loucura. Seu intuito não era oferecer uma conceitualização, tampouco uma classificação em termos de verdade daquilo que se entende como a loucura, mas sim compreender - a partir dessa analítica da exclusão dos corpos - as tecnologias dessa exclusão operadas sobre o louco. Assim, se na Idade Média os loucos haviam pertencido de certa forma ao horizonte social como aqueles que diziam a verdade da revelação de forma extravagante -, a partir da Renascença esses indivíduos teriam passado a ser reconhecidos de outro modo, sendo reagrupados a partir de uma nova unidade específica, delimitada por uma prática ambígua - de caridade e de repressão - na qual, ao lado de portadores de doenças venéreas, libertinos, blasfemadores e suicidas, eles seriam absorvidos numa massa indiferenciada. ${ }^{4}$

Foucault destacava que seria apenas a partir do advento da "Idade Clássica" no século XVII que a loucura passaria a ser socialmente esquadrinhada através da prática do isolamento. Esta ocorreria não devido à preocupação humanista com o cuidado do outro, mas sim a partir do surgimento de uma nova sensibilidade social ligada aos deveres da assistência, às novas formas de ação diante dos problemas econômicos do desemprego e da ociosidade, assim como de uma nova ética do trabalho e do sonho de uma cidade onde a obrigação moral se uniria à lei civil sob as formas autoritárias da coação. ${ }^{5} \mathrm{O}$ internamento, então, antes de ter o sentido médico que atualmente lhe é atribuído, foi exigido por razões bem diversas da preocupação com a cura.

A loucura passaria a ser percebida no horizonte social da pobreza, da inapt

\footnotetext{
${ }^{3}$ FOUCAULT, Michel. A História da Loucura na Idade Clássica. São Paulo, Perspectiva, 1997, p. 6.

${ }^{4}$ Ibidem, p. 135.

5 Ibidem, p. 565.
} 
idão para o trabalho e da impossibilidade de integração no corpo social, quando ela seria incorporada aos diagnósticos da razão e das regras da moral. Por isso, Foucault esclarecia que a relação que passou a se estabelecer no século XVIII entre o pensamento médico e a prática do internamento tinha mais a ver com essa nova sensibilidade diante da distância entre o louco e o corpus social do que no que dizia respeito a uma preocupação com a saúde mental dos alienados. Logo, o surgimento dos hospícios e da psicologia no século XIX se daria em consonância com o novo status público adquirido pela loucura naquele contexto. Confinados, os loucos não seriam um perigo para o restante da sociedade. O internamento, transformado em medicação, converteria o gesto negativo da exclusão no significado positivo da cura:

loucura só escapou ao arbitrário para entrar numa espécie de indefinido para o qual o asilo fornece ao mesmo tempo policiais, promotores, juízes e carrascos. Um processo onde toda falta da vida, por uma virtude própria à existência asilar, torna-se crime social, vigiado, condenado e castigado; um processo r.cuja única saída é um eterno recomeçar sob a forma interiorizada do remorso. O louco "libertado" por Pinel e, depois dele, o louco do internamento moderno, são personagens sob processo. Se têm o privil égio de não mais serem misturados ou assimilados a condenados, são condenados a estar, a todo momento, sujeitos a um ato de acusação cujo texto nunca é revelado, pois é toda a vida no asilo que o formula [...] A loucura será punida no asilo, mesmo que seja inocentada fora dele. Por muito tempo, e pelo menos até nossos dias, permanecerá aprisionada num mundo moral. ${ }^{6}$

Como percebido por Guilherme Providello e Silvio Yasui, a história da loucura de Foucault revelava não apenas o caráter descontínuo - e não progressivo - do surgimento psiquiatria e de sua interpretação da loucura, como também a complexidade de um eficaz mecanismo de controle e de exclusão social criado pelo discurso científico na modernidade ${ }^{7}$. Essa desnaturalização do discurso médico-científico - e da prática dos internamentos - operada por Foucault é fundamental para que compreendamos as relações de poder que serviram para legitimar as mais variadas práticas de controle e de segregação em realidades um tanto distintas da Era Clássica europeia descrita pelo intelectual francês. Um olhar sobre o caso capixaba, por exemplo, é bastante revelador dessa lógica foucaultiana de entendimento do trato com a loucura na modernidade.

\section{Exclusão social e caso de polícia: o trato com a loucura no Espírito Santo entre o fim do oitocentos e a primeira metade do século $\mathrm{XX}$}

Jabert divide em três momentos as formas da administração da loucura no Espírito Santo, sendo que o primeiro momento pode ser delimitado entre $1 . .887$ e 1898 . Nesses onze anos, os loucos era...jm internados em um asilo anexo à

\footnotetext{
${ }^{6}$ FOUCAULT, Michel. A História da Loucura... Op. cit., p. 546-547.

${ }^{7}$ PROVIDELLO, G. D.; YASUI, Silvio. A loucura em Foucault: arte e loucura, loucura e desrazão. História, Ciências, Saúde-Manguinhos (Impresso), v. 20, 1515-1529, 2013, p. 1516-1517.
} 
.Santa Casa de Misericórdia do Espírito Santo, o primeiro asilo de alienados em terras capixabas.

A primeira tentativa no sentido de prover atendimento voltado para os tidos como "anormais" foi em 1862: o chefe de polícia d..a capital solicitou à Provedoria que autorizasse a construção de um pequeno hospício, que seria gerido pelo provedor. No entanto, a direção da Santa Casa, que administraria o local, não aceitou a ideia, alegando falta de recursos. Desde pelo menos 1855, os alienados de Vitória foram encaminhados à Santa Casa, que internava essas pessoas junto aos outros enfermos do hospital. ${ }^{8}$ Entretanto, em 1862, a direção decidiu que os alienados não mais seriam acolhidos, pois o hospital não tinha estrutura física adequada para receber as pessoas com perturbações mentais. Alegavam, de acordo com Afonso Schwab e Mário Aristides Freire, que os loucos transtornavam e prejudicavam a rotina do hospital. Dessa forma, os alienados que não conseguiam ser atendidos pela Santa Casa eram enviados para serem internados no Rio de Janeiro, especialmente no Hospício Dom Pedro II.

Nesse contexto, o que se seguiu foi uma disputa entre o chefe de polícia e o presidente da província versus a administração da Santa Casa. Os primeiros tentavam obrigar legalmente o hospital a criar um pequeno hospício que deveria ser cuidado pela gerência daquela instituição. Os provedores da Santa Casa tentaram recorrer a várias instâncias - até ao Imperador Dom Pedro II - para evitar o cumprimento da lei. Entretanto, em 1866, perderam a disputa e foram obrigados a apresentar um projeto de construção de um pequeno sanatório, sob pena de serem cortados os recursos enviados pelo governo da província à instituição.

Mediante tal cenário, a Santa Casa apresentou um projeto, recebendo verbas da província para construir um asilo de alienados anexo ao hospital. Contudo, as obras não foram executadas de imediato e o espaço destinado aos pacientes com problemas mentais só foi inaugurado em 1887, ou seja, mais de vinte anos após o início da querela entre o governo provincial, os chefes de polícia e a administração do hospital. ${ }^{9}$

Com a inauguração do espaço destinado aos loucos, os problemas não terminaram, visto que os alienados não recebiam o tratamento demandado pelos padrões médicos da época. ${ }^{10} \mathrm{O}$ estabelecimento se limitou a isolar e a encarcerar os doentes mentais naquele recinto. Praticamente só eram cuidados quando acometidos corporalmente por alguma

\footnotetext{
${ }^{8}$ PIVA, Izabel M. da P.; SIQUEIRA, Maria da Penha S. Santa Casa da Misericórdia de Vitória: ação da irmandade no atendimento à pobreza em Vitória - ES (1850-1889). Revista Ágora, Vitória, n. 2, 2005.

${ }^{9}$ SCHAWB, Afonso; FREIRE, Mário Aristides. A irmandade e a Santa Casa da Misericórdia do Espírito Santo. Vitória: Arquivo Público Estadual, 1979.

${ }^{10} \mathrm{~A}$ menção às práticas terapêuticas desenvolvidas nas instituições hospitalares serve, neste artigo, para ilustrar o elemento maior que objetivou a escrita deste trabalho, qual seja, a exclusão social oriunda da repressão policial e de um projeto de cidade que segregava os ditos indesejáveis. Tal discurso e finalidade foram mimetizados pelo suposto tratamento terapêutico que seria oferecido aos acometidos pelas moléstias mentais. Sem querer fugir do foco do artigo mencionado acima, explicitamos, rapidamente, algumas práticas terapêuticas que se alinhavam aos ditames repressivos do ideal de cidade moderna e que destoavam das práticas médicas à época: remédios armazenados em condições pouco higiênicas, dependências hospitalares em formato de jaula, sem asseio, que serviam apenas de depósito de pessoas doentes.
} 
moléstia não ligada à saúde mental. ${ }^{11}$ Segundo Jabert, a Santa Casa de Misericórdia justificava tais práticas explicando que contava com apenas um médico para atender todos os doentes internados, incluindo os loucos. ${ }^{12}$

Já no período republicano, José de Melo Carvalho Muniz Freire - que ocupou o cargo de presidente de estado entre 1892 e 1896 - apresentou, na tentativa de alterar o quadro de saúde pública referente aos loucos, um projeto de construção de hospital de caridade, o qual seria sustentado pelo Estado. Dessa maneira, o então presidente definiu que a instituição teria parte de sua estrutura projetada para receber os alienados. Tal medida estava na esteira das questões postas ao final do Império e no início do regime republicano brasileiro, sobretudo no que dizia respeito à tentativa de separar Estado e Igreja.

Contudo, a obra não foi concluída sob a alegação de falta de verbas, pois o estado capixaba viveu uma crise econômica na virada do século XIX para o XX por depender amplamente da cafeicultura. ${ }^{13}$ Diante disso, a situação em que os pacientes alienados viviam agravava-se. De acordo com o depoimento do provedor da Santa Casa de Misericórdia, Valdemiro Fradesso da Silveira, que assumiu o cargo em 1898:

A entrada do Hospital tinha o aspecto de uma dependência de cadeia civil ou do corpo de polícia: - ao lado um compartimento que servia de enfermaria, um verdadeiro cárcere, coberto de andrajos, com alguns presos guardados por uma guarda que ali fazia seu refeitório e dormitório, sem asseio, sem ordem e onde à luz meridiana se cometiam cenas que a decência manda calar. Mais adiante um compartimento separado por uma grade de sarrafos de pinhos pintada de amarelo com algumas prateleiras em completa ruina, vidros sem rótulos, outros sem rolhas, tudo em promiscuidade, sem a menor noção de asseio, diziam - é a farmácia. Do lado oposto um outro compartimento separado por igual grade, de igual pintura, dentro um pobre velho octogenário arrastando os pés, o Administrador - Consultório Médico. Srs. Irmãos, não vos descrevo as enfermarias porque teria de arrancar-vos um brado de indignação. A dependência do Hospital denominada impropriamente - Asilo de Alienados - era

\footnotetext{
${ }^{11}$ JABERT, Alexander. Formas de administração... Op. cit., p. 698.

${ }^{12} \mathrm{~A}$ percepção exposta neste trecho por Alexander Jabert reflete o ponto de vista dos médicos do final do século XIX brasileiro que, pelo menos desde o início do oitocentos buscavam a hegemonia entre as práticas terapêuticas. É importante ponderarmos que o número de médicos não era necessariamente visto pela população, em geral, como um agravante para os quadros da saúde pública. Especialmente entre os mais pobres, as práticas de cura não-oficiais (mezinheiros, curandeiros, parteiras, barbeiros, entre outras) configuravam entre as primeiras alternativas de cura. A afirmação da autoridade dos esculápios, portanto, não foi algo dado. Esse espaço foi paulatinamente conquistado principalmente pelas estratégias adotadas pelos médicos junto ao estado, à população e aos demais setores da sociedade. Vale lembrar que mecanismos de validação da sua disciplina foram sendo aperfeiçoados por esses profissionais a medida que os saberes acumulados serviram de subsídio para o aumento da eficácia dos tratamentos apresentados à população. Sobre o assunto as práticas de cura oficiais e não-oficiais. Sobre este tema, ver: WEBER, B. T. As Artes de Curar no Brasil: medicina, religião e positivismo na República Rio-Grandense (1889-1928). Santa Maria, RS; Bauru, SP: Ed. UFSM; Editora da Universidade do Sagrado Coração, 1999; WILTER, N. A. Curandeirismo: Um outro olhar sobre as práticas de cura no Brasil do século XIX. Revista Vidya, v. 19, n. 34, jul. 2000; SAMPAIO, G. R. A história do feiticeiro Juca Rosa: cultura e relações sociais no Rio de Janeiro imperial. 2000. Tese (Doutorado em História) - Instituto de Filosofia e Ciências Humanas, Universidade Estadual de Campinas, Campinas; Idem. Nas trincheiras da cura: as diferentes medicinas no Rio de Janeiro Imperial. Campinas, SP: UNICAMP, 2001; MARQUES, V. B.; SAMPAIO, G. R.; GALVÃO SOBRINHO, C. (orgs.). Artes e ofícios de curar no Brasil: capítulos de história social. Campinas, SP: Ed. UNICAMP, 2003; NOGUEIRA, A. Entre cirurgiões, tambores e ervas. Calunduzeiros e curadores ilegais em ação nas Minas Gerais (século XVIII). Rio de Janeiro: Garamond, 2016.

${ }^{13}$ SANTOS, Estilaque Ferreira dos. José de Melo Carvalho Muniz Freire. Vitória: Espírito Santo em Ação, 2012.
} 
uma verdadeira jaula, sem higiene, sem tratamento apropriado, onde o desamparado da sorte só aguardava o dia da morte. O meu primeiro cuidado foi eliminar essa classe de enfermos; para isso recorri ao digno Chefe de Polícia Dr. Sergio Loreto, a quem expus a situação desses infelizes. S. Ex. deu todas as providencias, de modo que no dia $1^{\circ}$ de setembro, a bordo do vapor Muquy, seguiram os alienados para o Hospício no Rio de Janeiro. ${ }^{14}$

Em que pese a falta de vontade política e os problemas financeiros, o provedor da Santa Casa descrevia a situação dos alienados na instituição sob sua responsabilidade como se encontrando em uma situação um tanto degradante. Feitas as devidas ressalvas, o relato acima nos permite construir algumas balizas para compreendermos o lugar dos loucos na sociedade capixaba: "uma verdadeira jaula, sem higiene, sem tratamento apropriado, onde o desamparado da sorte só aguardava o dia da morte". Diante de tal quadro, só nos resta concordar com o provedor que a situação não era a mais adequada. A partir disso, qual a solução foi encontrada para tal mazela? Infelizmente, essa querela ainda estava longe de ser resolvida.

Mediante as dificuldades financeiras, a Santa Casa de Misericórdia fechou o setor que cuidava dos loucos, e o Estado do Espírito Santo passou os vinte anos seguintes sem lugar específico para abrigar doentes mentais, exportando-os para o Hospital Nacional de Alienados, no Rio de Janeiro.

Assim, os alienados voltaram a ser confinados no quartel de polícia da capital e alguns eram de lá transferidos para a então capital federal. Seria nesse momento, entre 1899 e 1921 , que se iniciaria o segundo momento da administração da loucura no Espírito Santo. ${ }^{15} \mathrm{O}$ governo estadual tentaria estabelecer medidas de amparo à população com problemas mentais, apesar da inexistência de uma instituição específica para internamento dos loucos em território capixaba.

O que se percebe nos trabalhos e fontes sobre esse período é que a questão se tornara, em muitos momentos da primeira metade do século $X X$, uma disputa entre a justiça e os quartéis de polícia, sendo estes últimos sempre muito atuantes na condução dos indivíduos que preenchiam os espaços destinados aos corpos desviantes. O quartel policial assumiria também, em momentos de hiato das instituições terapêuticas, a responsabilidade da administração dos alienados. ${ }^{16}$

\footnotetext{
${ }^{14}$ Relatório do Provedor Valdemiro Fradesso da Silveira apresentado à Mesa Diretora da Irmandade da Misericórdia em 1899. Arquivo Público do Estado do Espírito Santo (APEES), Fundo Governadoria, série 383, p. 9.

15 JABERT. Alexander. Formas de administração... Op. cit.

${ }^{16} \mathrm{~A}$ justiça e a polícia se apresentavam na condição de fiscais dos hábitos da população desviante em outros locais do Brasil. Em sua obra Meninas perdidas: os populares e o cotidiano do amor no Rio de Janeiro da Belle Epoque, Martha A. Esteves demonstra como o poder judiciário tinha seus padrões morais bem definidos e por meio deles conhecia os modelos comportamentais desejáveis para as pessoas do início do século XX, especialmente para as mulheres. Para mais informações, ver: ESTEVES, Martha de Abreu. Meninas Perdidas: os populares e o cotidiano do amor no Rio de Janeiro da Belle Époque. Rio de Janeiro: Paz e Terra, 1989. No Espírito Santo, o controle social foi assumido pela Justiça e pela Polícia; os médicos pouco interferiam nessa questão no início do século XX. Segundo os estudos de Jabert, os requerimentos para transferência de pacientes com problemas mentais eram majoritariamente produzidos por delegados, juízes, promotores, sendo raros os documentos desse tipo encontrados que foram preenchidos por médicos. JABERT. Alexander. Formas de administração... Op. cit.
} 
A medida tomada para modificar o quadro exposto foi o início da obra de um novo hospital em 1910. Entretanto, no projeto original da casa de saúde não estava prevista a construção da ala para alienados, em função disso, uma querela entre a diretoria do hospital da Santa Casa e o governador do Estado, Jerônimo Monteiro, ${ }^{17}$ se desencadearia, pois, os diretores não queriam a responsabilidade de cuidar dos loucos. Por outro lado, o Estado os pressionaria a ceder parte do terreno para construir um nosocômio, pois essa seria uma forma de compensar os gastos do governo com as obras do novo hospital. ${ }^{18}$

Diante dessa situação, a diretoria da Santa Casa preferiria romper o contrato com o governo do Estado a abrigar o manicômio sob sua responsabilidade. Consequentemente, os loucos capixabas permaneceriam encarcerados no quartel de polícia. Segundo Jabert, alguns alienados continuariam sendo enviados para o Hospital Nacional dos Alienados, no Rio de Janeiro, de navio. As transferências eram requisitadas pelos policiais do quartel da capital. Ou seja, parte dos alienados continuaram a ser caso de polícia no início do século XX no Espírito Santo.

Até 1921, portanto, era bastante comum o envio de loucos espírito-santenses para o Rio de Janeiro, embora as autoridades locais clamassem pela construção de um espaço para tratamento dos transtornos mentais. Importa frisar que, assim como a capital federal recebia alienados de outras partes do país, Vitória acolhia loucos que vinham do interior do estado para serem acondicionados nas cadeias da cidade. À medida que o acesso à cidade melhorava, com a construção de estradas e ferrovias, mais alienados chegavam à capital:

O delegado geral de polícia da capital, em 1927, pedia mais uma vez que se criasse um asilo em Vitória, pois, segundo ele, era "bem elevado o coeficiente de doentes mentais, indigentes ou não, no nosso Estado, além daqueles procedentes da extensa zona mineira, servida pela Estrada de Ferro Victoria Minas. ${ }^{19}$

Ao lado das constantes reclamações das autoridades policiais, o hospital da capital federal nem sempre possuía vagas para atender a todos os pedidos do Espírito Santo. A cadeia do quartel de polícia também era inadequada para receber os alienados, afora a superlotação

\footnotetext{
17 Jerônimo Monteiro nasceu em 1870 em Cachoeiro de Itapemirim (ES) no seio de uma família da elite cafeeira local. Cursou Direito em São Paulo, concluindo o curso em 1894. Em 1895, foi eleito deputado estadual pelo Partido Republicano Construtor (PRC), que governava o Espírito Santo. Entre 1897 e 1899, elegeu-se deputado federal pelo mesmo partido. Em 1900, Monteiro compunha os quadros do partido que ele ajudara a fundar, o Partido da Lavoura (PL). Durante o governo de Henrique Coutinho (19041908), Monteiro construiu relações com o então presidente, prestando-se a negociar dívidas e outros assuntos de interesse do Espírito Santo, o que construiu sua imagem como importante articulista dos interesses locais. Posteriormente, foi lançado pelo PRC para concorrer como presidente de estado. Monteiro elegeu-se e governou entre 1908 e 1912. Seu mandato foi marcado por várias transformações: remodelou o sistema educacional, inaugurou o Arquivo Público Estadual, promoveu a instalação de indústrias no Sul do estado, estruturou os serviços de abastecimento de água, recolhimento de esgoto e implementação da energia elétrica na cidade de Vitória. Após ocupar o cargo de presidente de estado, o político cachoeirense ainda permaneceria na vida pública assumindo cargos de deputado estadual, deputado federal e senador.

18 JABERT, Alexander. Formas de administração... Op. cit.

${ }^{19}$ Relatório da Repartição Central de Polícia, Delegado Geral dr. Fernandes D. Rabello em 1927. APEES, Relatórios Gerais do Estado do Espírito Santo, p. 41.
} 
de criminosos. Nas primeiras décadas do século $X X$, portanto, além de um manicômio, urgia a construção de um presídio na capital capixaba.

Na última fase de 1921 até o fim da primeira república, destacar-se-ia a parceria entre o governo estadual e o Asilo Deus, Cristo e Caridade - coordenado por Jerônimo Ribeiro. Essa instituição filantrópica localizava-se em Cachoeiro de Itapemirim, ${ }^{20}$ e para lá eram enviados os pacientes com transtornos mentais que saíam de Vitória de trem. Entretanto, esse convênio não indicava a transferência da responsabilidade da administração da loucura para os médicos psiquiatras no Espírito Santo. Podemos inferir, portanto, que a polícia continuava atuando nesse problema social causado pela loucura. ${ }^{21}$

Durante o governo de Nestor Gomes (1920-1924), o Estado manteria a parceria que possuía o intuito de enviar alienados da capital Vitória para o asilo coordenado por Ribeiro. Com essa medida, o poder público novamente adiaria a construção de um espaço adequado para receber e tratar seus doentes mentais. Em troca, o governo do Estado passaria a financiar parte da construção do pavilhão para receber os loucos. Essa parceira foi criticada por autoridades públicas, visto que a instituição não seria coordenada por médicos - o asilo era dirigido por uma associação de espíritas -, afora ser a estrutura inadequada para oferecer cuidados aos alienados.

No entanto, mesmo com carências nas estruturas do asilo e a falta de pessoal qualificado para tratar os loucos, no primeiro ano do convênio, entre 1921 e 1922, cerca de trinta pacientes foram enviados para lá, e já no segundo ano, entre 1922 e 1923, cerca de cento e dez alienados foram transferidos do quartel de polícia da capital para Cachoeiro. ${ }^{22}$

Essa vazão de pessoas permitiria que os loucos fossem retirados da cadeia civil subsidiando um funcionamento mais organizado da instituição, já que eles seriam responsáveis pela causa de vários transtornos na manutenção da disciplina. A coerção policial passou a ter mais recursos, pois o gasto para manter os doentes mentais e prisioneiros comuns seria totalmente redirecionado para a segurança pública.

A nova demanda para os policiais foi o recolhimento de mendigos na capital, que também passaram a ser enviados para o asilo fundado por Jerônimo Ribeiro. Para se ter uma ideia, segundo os relatórios de polícia do ano de $1928,{ }^{23}$ no ano anterior, haveria cento e quarenta e seis internamentos no asilo de Cachoeiro.

Malgrado tais resultados, as críticas à falta de terapias mais modernas eram frequentes. Vários problemas não seriam sanados nessa parceria entre o governo estadual e o Asilo Deus, Cristo e Caridade. Os policiais continuariam reclamando por terem que encarcerar loucos na cadeia com prisioneiros, além das dificuldades no transporte para a cidade de Cachoeiro. Ademais, o asilo tampouco aplicava adequadamente todos os recursos enviados pelo Estado, ou seja, o governo financiava apenas os cuidados aos doentes mentais, mas os diretores do

\footnotetext{
${ }^{20}$ Cidade ao sul do Espírito Santo localizada a cerca de $140 \mathrm{~km}$ da capital Vitória.

21 JABERT. Alexander. Formas de administração... Op. cit.

${ }^{22}$ Idem.

23 JABERT, Alexander. Da Nau dos Loucos ao Trem de Doido. 2011. Dissertação (Mestrado em Ciências da Saúde) - Programa de Pós-Graduação em Ciências da Saúde, Fundação Oswaldo Cruz, Rio de Janeiro.
} 
asilo usavam essas verbas também em pavilhões de idosos e órfãos. Desta forma, o dinheiro enviado tornava-se insuficiente para o tratamento digno dos alienados.

Diante desses transtornos se tornaria crescente a necessidade de se criar um hospital psiquiátrico no Espírito Santo. De todo modo, Florentino Avidos, durante seu governo, de 1924 a 1928, alegava que não haveria verba suficiente para a construção do referido asilo. ${ }^{24}$

Como se não bastasse, em 1929, a situação pioraria ainda mais, pois a população de indigentes crescia na capital e a solução continuava a mesma, qual seja, enviar a maioria dos alienados capixabas para o Asilo Deus, Cristo e Caridade, em Cachoeiro de Itapemirim, e para o hospital Dom Pedro II, no Rio de Janeiro. Mesmo essas não sendo as medidas mais eficientes para resolver o problema, eram as que se mostravam financeiramente mais confortáveis.

O caso do Espírito Santo em relação à forma como se administrava a loucura não era incomum. O Anuário Estatístico do Brasil, de 1937, publicado pelo Instituto Brasileiro de Geografia e Estatística (IBGE), apontava em 1932 sete estados sem instituição específica para o cuidado de alienados, sendo que desses sete, dois estados - Maranhão e Ceará - geriam o problema social causado pela loucura de maneira similar ao governo capixaba.

Analisando informações sobre a situação de pessoas consideradas loucas na Primeira República no Brasil, infere-se que a exclusão marcava a forma pela qual esses indivíduos eram tratados pelo Estado e pela sociedade. Apesar de não terem cometido crimes, os loucos eram tidos como indesejáveis, isto é, como indivíduos que viviam de forma incompatível com os padrões da sociedade, tendo os debates a respeito da construção de um hospital na primeira metade do século $X X$, tido esse tipo de imaginário repressivo como pano de fundo. ${ }^{25}$

No contexto do Estado Novo, em 1941, seria criado o Serviço Nacional de Doenças Mentais (SNDM), o qual passaria a estabelecer parcerias com as Secretarias de Saúde dos estados do Brasil. Essa medida verticalizada e centralizadora reduzia a autonomia dos políticos locais no campo da saúde e levava os tentáculos do governo federal aos mais longínquos lugares do país, que por meio da organização política dos Serviços Nacionais estruturou estratégias de ação durante a administração Varguista. ${ }^{26}$ Assim, em meio a protestos dos

\footnotetext{
${ }^{24}$ Embora Florentino Avidos alegara não ter recursos para efetuar a construção de um hospital para os alienados, sua gestão foi marcada por inúmeras obras modernizadoras na capital. Em seu governo ruas foram alargadas, viadutos e pontes construídos, redes de esgoto e drenagem foram efetuados, obras no porto foram realizadas, bairro foram construídos e vias que ligavam a região periférica da cidade ao Centro foram abertas. Em meio a tantas transformações espaciais, um novo código de posturas foi promulgado. Sobre tal episódio, podemos inferir que a cidade estava se modernizando, o que não significava uma ampliação dos espaços inclusivos tampouco a garantia do exercício da cidadania. A gestão pública não foi eficiente nesse sentido e mais, contribuiu para produzir a estigmatização do louco em nossa sociedade. Cf.: SALETTO, Nara; ACKERMANN, Sílvia R. Florentino Avidos. (Verbete). In: ABREU, A. A.; CARNEIRO, A. D. (orgs.). Dicionário Histórico-Biográfico Brasileiro da Primeira República 1889-1930. Rio de Janeiro: FGV, 2015.

${ }^{25}$ CARRION, Carla. Desalinhados: uma história do Hospital Adauto Botelho e das memórias que ali habitam. 2011. Dissertação (Mestrado em Psicologia) - Programa de Pós-Graduação em Psicologia Institucional, Universidade Federal do Espírito Santo, Vitória.

${ }^{26}$ Para mais informações sobre os Serviços Nacionais criados no primeiro governo de Getúlio Vargas, ver: FONSECA, Cristina M. O. Saúde no Governo Vargas (1930-45): Dualidade Institucional de um Bem Público. Rio de Janeiro: Ed. Fiocruz, 2007; FABRÍCIO, André Luiz da Conceição. A Assistência Psiquiátrica no Contexto das Políticas Públicas de Saúde (1930-1945): o caso da Colônia Juliano Moreira. 2009. Dissertação (Mestrado em História das Ciências e da Saúde) - Fundação Oswaldo Cruz, Rio de Janeiro.
} 
governadores do Espírito Santo, em 1944, seria criado, em terras capixabas, o Serviço de Assistência aos Psicopatas. Junto a esse serviço se encontraria o Hospital do Psicopata, integrado ao Hospital Osvaldo Monteiro na Ilha da Pólvora, em Santo Antônio, na Baía de Vitória. Esse hospital abrigaria alienados transferidos do Asilo Deus, Cristo e Caridade, servindo também como local de tratamento e de isolamento de pessoas com hanseníase e tuberculose.

Conforme atestado nas fontes e em relatos da época, as instalações daquele asilo na Baía de Vitória eram de difícil acesso a pacientes, funcionários e familiares, e as condições físicas do hospital não eram as melhores, pois faltavam leitos para a alta demanda, além de haver constantes afogamentos de doentes que tentavam fugir do local. Seria necessária ainda uma década para que uma instituição de saúde aos moldes modernos se instalasse na capital capixaba a fim de sanar o problema social da loucura.

\section{A modernização do trato com a loucura no Espírito Santo: a inauguração do Hospital Colônia Adauto Botelho}

No intuito de superar as insuficiências no campo da saúde pública voltada para os alienados, entre 1945 e 1954, o médico Adauto Botelho, ${ }^{27}$ diretor do Serviço Nacional de Saúde Mental, se empenharia na construção de um hospital colônia no Espírito Santo. No mesmo período, seriam construídas outras instituições com modelos arquitetônicos parecidos em Goiás e Pernambuco, que também receberiam o nome do médico mineiro. ${ }^{28}$

As obras foram iniciadas durante o governo de Carlos Lindenberg, em 1949, tendo sido concluídas em 1954, já durante o governo de Jones dos Santos Neves. O governo estadual concederia mão-de-obra e terreno, enquanto a Secretaria Nacional de Doentes Mentais cederia recursos financeiros obtidos junto à união a fim de auxiliar na empreitada.

A inauguração do Hospital Colônia Adauto Botelho aconteceria, portanto, no dia 24 de abril de 1954, contando com a presença do ministro da saúde, Miguel Couto Filho, que classificaria o hospital como "moderno e bem equipado", com todos os recursos técnicos

\footnotetext{
${ }^{27} \mathrm{O}$ doutor Adauto Junqueira Botelho formou-se em Psiquiatria pela Faculdade Brasileira de Medicina na Universidade Brasileira, situada no Rio de Janeiro, em 1917. Foi bastante atuante na vida acadêmica, na administração psiquiátrica e na clínica privada. Fundou, junto com outros psiquiatras, o Sanatório Botafogo. Foi assistente de Henrique Roxo, discípulo de Juliano Moreira e atuou politicamente durante o governo de Getúlio Vargas, criando o Serviço Nacional de Doenças Mentais (SNDM). Além disso, participou e foi o primeiro presidente da Associação Brasileira de Psiquiatria Brasileira. Durante dois anos foi catedrático interino da Universidade do Brasil atual UFRJ. Foi editor dos Arquivos que eram publicados pelo SNDM. Foi responsável pela criação de 22 ambulatórios públicos. Foi também diretor da Assistência aos Alienados e fundador do Centro Psiquiátrico de Engenho de Dentro, para onde foram transferidos alguns pacientes do Hospital Nacional de Alienados. Botelho também contribuiu para a reestruturação do Departamento Nacional de Saúde. Coordenou a instalação de hospitais-colônias em vários locais do Brasil. Faleceu em fevereiro de 1963.

${ }^{28}$ SECRETARIA da Saúde do Estado do Espírito Santo. 50 Anos Adauto Botelho: Resgate da Memória do Hospital Adauto Botelho. Vitória, 2004.
} 
necessários para atender com dignidade os pacientes lá internados. No mesmo dia, uma reportagem do jornal $A$ Gazeta, ${ }^{29}$ informava que:

Manoel Moreira Camargo para declarar que, tendo comparecido à inauguração do Hospital Colônia Professor Adauto Botelho, como representante da Câmara Municipal de Vitória, desejava congratular-se com os governos da República e do Estado, bem como com os doutores Adauto Botelho e Alaor Queiroz de Araújo pela concretização de tão notável obra que veio, sem dúvida, preencher uma grande lacuna em nosso Estado no tocante à solução do problema dos alienados. Adiantou que, quem comparecer em Santana, sentir-se-á entusiasmado com a majestade e a imponência do edifício que está dotado dos mais modernos requisitos da técnica, merecendo, como recebeu do Sr. Ministro da Saúde, a merecida classificação de Hospital Modelo. E oportuno, frisou lembrar, aqui, para conhecimento de todos os capixabas, que o projeto é de autoria de um modesto arquiteto contemporâneo, Olímpio Brasiliense. Finalizando, declarou que seria interessante se antes de ser definitivamente instalado o Hospital, fosse o mesmo visitado e admirado por quantos se interessassem pelo bem-estar dos infelizes doentes, atacados das faculdades mentais, atualmente em número superior a 300 , o mesmo passo que fazia voto por que o Governo Federal continue a emprestar a sua ajuda para tão grandiosa e humanitária obra. ${ }^{30}$

Tanto o vocabulário como as manifestações expressas pelo representante da Câmara Municipal de Vitória, Manoel Moreira Camargo, remetiam a apontamentos para aquele que seria um futuro diferente em relação ao trato com a saúde mental dos capixabas. Conforme mencionado no excerto acima, - "tão notável obra que veio, sem dúvida, preencher uma grande lacuna em nosso estado no tocante à solução do problema dos alienados" - a construção do novo hospital parecia anunciar uma ruptura em relação a antigas práticas de trato com a loucura em nosso estado.

Por isso, acreditava-se inaugurar naquele momento um período de inflexão, no qual o Espírito Santo passaria a se inserir em um novo tempo no que tangia aos cuidados com a saúde mental. A partir de então, portanto, o estado estaria "dotado dos mais modernos requisitos da técnica" para melhor atender aos capixabas. Tal horizonte de expectativa era altamente otimista, ${ }^{31}$ pois visava o "bem-estar dos infelizes doentes" e "emprestava a sua ajuda para tão grandiosa e humanitária obra". Em outras palavras, a técnica e os aparatos modernos do hospital supririam as lacunas deixadas pela negligência e pelo atraso dos anos anteriores.

\footnotetext{
${ }^{29}$ Jornal impresso com expressiva circulação no estado do Espírito Santo, fundado em setembro de 1928.

${ }^{30}$ Artigo "Obra notável o Hospital Colônia -Adauto Botelho" publicado no periódico em: A Gazeta, Vitória, 29 abr. 1954.

31 A categoria "horizonte de expectativa", cunhada pelo historiador alemão Reinhart Koselleck, diz respeito à maneira como os indivíduos desenvolvem sua relação com o futuro em cada contexto específico. No caso da modernidade europeia (1750-1850), estudado pelo autor, os sentimentos positivos estavam na ordem do dia, pois se apoiavam nos avanços proporcionados pelas técnicas e pelo desenvolvimento das ciências. Nas palavras de Koselleck: "a expectativa se realiza no hoje, é futuro presente, voltado para o ainda-não, para o não experimentado, para o que apenas pode ser previsto. Esperança e medo, desejo e vontade, a inquietude, mas também a análise racional, a visão receptiva ou a curiosidade fazem parte da expectativa e a constituem." In: KOSELLECK, Reinhart. Futuro Passado: Contribuição à semântica dos tempos históricos. Rio de Janeiro: Contraponto; PUC-Rio, 2006, p. 310.
} 
No dia seguinte à referida matéria, o jornal mais uma vez trataria da infraestrutura do prédio da nova instituição sob a ótica de quem enxergava a concretização de um feito moderno, afirmando que a mesma teria sido:

Projetado por Olímpio Brasieliense, arquiteto capixaba, tinha a estrutura e arquitetura semelhante aos demais hospitais psiquiátricos construídos em outras capitais, cujo modelo foi inspirado na concepção francesa, postulada por Esquirol. Sob a forma de um retângulo, o hospital foi dividido em duas partes simétricas, tendo um bloco central separando as alas femininas e masculinas. ${ }^{32}$

Ainda tomado pela mesma lógica da época da inauguração, o ex-diretor, Alcides Pereira Silva, que assumiu o cargo nos períodos de 1963 a 1964 e de 1975 a 1976, ressaltava que o hospital não beneficiaria apenas a população local, pois atenderia a um público de diversas origens, incluindo até mesmo os estrangeiros sob os seus cuidados. Ademais, destacava a instituição como uma genuína política de estado por ser mantida exclusivamente pela administração pública:

O hospital foi situado em uma ampla faixa de terra, no município de Cariacica, no sopé de uma colina na fazenda Santana, e se destinava ao tratamento de psicopatas. Inicialmente, a finalidade era atender a pacientes do Espírito Santo. Mas conforme o livro de registro de 1954 de entrada de pacientes, constatou-se que o hospital atendeu a pacientes do sul da Bahia, interior de Minas Gerais, Rio de Janeiro, Paraíba, Recife e Rio Grande do Norte, bem como estrangeiros provenientes da Itália, Líbia, Alemanha, Síria, sendo mantidos quase exclusivamente pelo Estado, com uma despesa mensal de aproximadamente 100 milhões de cruzeiros. ${ }^{33}$

Alcides P. Silva reverberava em sua fala os depoimentos de empregados que haviam trabalhado nos primeiros anos de funcionamento do hospital. Estes descreviam o local como um perfeito bastião da modernidade, de modo que, as tecnologias disponíveis à época eram apresentadas como uma espécie de cenário ideal para a prática da medicina e para os cuidados em relação aos pacientes.

Entretanto, o ex-diretor não escondia os contrastes dessa moderna instituição com o seu entorno, pensado sob a lógica da exclusão, devido, sobretudo, à sua distância em relação ao centro da capital e por suas precárias vias de acesso: ${ }^{34}$

O hospital era dotado de instalações e equipamentos clínicos, centro cirúrgico, laboratório de análises, salas de raios- $X$, sala de necropsia, gabinete dentário e serviço de estatística. $O$ acesso ao hospital era através de uma via de chão de

\footnotetext{
32 Obra notável o Hospital Colônia -Adauto Botelho. A Gazeta, Vitória, 29 abr. 1954.

${ }^{33}$ SILVA, Alcides Pereira apud SECRETARIA da Saúde do Espírito Santo. 50 Anos Adauto... Op. cit., p. 12.

${ }^{34}$ Nas décadas de 1940 e 1950 grandes transformações aconteceram em Vitória: o porto foi oficialmente organizado, levas de migrantes chegaram à cidade, indústrias e estabelecimentos comerciais foram instalados e o espaço ia sendo reorganizado. Em meio a essas transformações, a mendicância era citada pelos jornais locais da época como um problema que passava a existir na cidade. MARGOTTO, Lilian Rose. Transformações do espaço urbano sob o olhar da imprensa: a chegada dos "forasteiros" e do progresso à cidade de Vitória (ES, 1940-1960). Dimensões - Dossiê: Autoritarismo, repressão e memória II -, Vitória, n. 13, 51-59, jul./dez. 2001. Portanto, juntando as informações, é possível pensar: a cidade transformava-se e o hospital Adauto Botelho, possivelmente, foi bastante útil nesse cenário de "limpeza" do centro urbano, livrando-o dos indesejáveis e dos indigentes, de preferência afastando-os da maior concentração urbana, já que o manicômio estava localizado em uma região distante cerca de 12 quilômetros do Centro de Vitória.
} 
barro, escorregadia nos dias de chuva, o que impossibilitava o acesso de carros. $^{35}$

De todo modo, nas entrelinhas, fica claro que o cenário primoroso em quesitos técnicos, tecnológicos e humanitários se mostrava não tão ideal ou civilizado quanto a modernidade burguesa havia pregado. Na realidade, como veremos a seguir, longe de ter representado a tão aclamada modernização da medicina em nosso estado, o Hospital Colônia Adauto Botelho manteria vivas as velhas práticas que haviam até então marcado o tratamento da loucura por estas terras.

\section{Perpetuando a exclusão: uma análise do perfil dos primeiros pacientes no Hospital Colônia Adauto Botelho e dos principais critérios para a sua internação}

No que diz respeito à situação da estrutura e das condições apresentadas aos pacientes do novo sanatório, Milena Fiorim de Lima, colheu depoimentos de seus primeiros funcionários e relatou, em sua pesquisa que as instalações da instituição possuíam extensos corredores, salas frias, quartos pequenos sem janelas, onde os pacientes em crise eram temporariamente confinados e cujas portas eram trancadas com grades e cadeados. Em uma entrevista concedida por um dos antigos funcionários à pesquisadora é possível constatar: "a planta física dos locais são sem luz e aquelas pessoas são meio escondidas de todo mundo [...]. No imaginário social elas estão sendo tratadas, mas num lugar que fica entre o céu e a terra, que não existe." ${ }^{\prime 36}$

Lima ouviu também os profissionais de apoio. Estes diziam que nos primeiros anos de funcionamento do nosocômio não existiam máquinas de lavar roupa e, portanto, toda roupa de cama, banho e vestimentas eram lavadas à mão, demonstrando falhas na infraestrutura hospitalar, outrora tão elogiada pela imprensa. A isso, acrescia-se a falta de leitos e de colchões para os pacientes, sendo que alguns dormiam no chão. O tratamento dispensado aos pacientes, segundo Lima, demarcava claramente a condição social de cada indivíduo alocado naquele recinto: "havia, na época, três tipos de atendimento: um para os pacientes que podiam pagar, um para os que possuíam vínculo com a Previdência Social e um para os chamados indigentes. Para os últimos não restavam camas ou colchões e a comida era basicamente canjiquinha ou sopa de macarrão."137

Mas o que explica essas más condições e a segregação social verificável já nos primeiros anos de funcionamento da instituição?

$\mathrm{Na}$ primeira metade do século $X X$, na cidade de Vitória, surgiram demandas relacionadas à necessidade de se retirar das ruas pessoas incômodas que se punham como um

\footnotetext{
${ }^{35}$ SECRETARIA da Saúde do Espírito Santo. 50 Anos Adauto... Op. cit.

${ }^{36}$ LIMA, Milena Fiorim. Nos caminhos da psicologia capixaba: notas para a história da psicologia, da psiquiatria e saúde pública no estado do Espírito Santo. 2005. Dissertação (Mestrado em Psicologia) Programa de Pós-Graduação em Psicologia, Universidade Federal do Espírito Santo, Vitória, p. 39.

${ }^{37}$ Idem.
} 
empecilho ao projeto de cidade pretendido pelas classes dominantes. Diante disso, muitos desses indivíduos seriam enviados para o novo hospital do estado.

Essas informações estão contidas nos prontuários analisados por Carla Torres Carrion e nas entrevistas feitas com os funcionários que trabalharam no Adauto Botelho nos períodos subsequentes. Fica explícito nas entrevistas em questão que os critérios para internar pessoas naquele hospital se baseavam muito mais em aspectos socioeconômicos específicos do que em questões propriamente relacionadas à saúde mental. ${ }^{38}$

Além disso, cruzando informações obtidas dos anos de 1954, 1955 e 1956 retiradas do livro de entrada dos pacientes do hospital, é possível perceber como essa instituição de tratamento de alienados continuou a perpetrar antigas práticas de controle, repressão e exclusão de indivíduos considerados indesejáveis, só que desta vez, sob a tutela e o discurso de autoridade do saber médico local.

Como exemplo de tal assertiva temos alguns dados acerca das principais características dos internos entre os anos de 1954 e 1956, momento em que o livro de entrada do hospício discriminava algumas informações a respeito do perfil dos ingressos na instituição.

Em termos gerais, durante o primeiro ano de sua existência, o hospital recebeu 537 pessoas, sendo 298 homens e 239 mulheres: ${ }^{39}$

Quadro 1 - Internos do hospital por ano

\begin{tabular}{|l|c|c|c|}
\hline \multicolumn{1}{|c|}{ Ano } & Sexo Feminino & Sexo Masculino & Total \\
\hline $\mathbf{1 9 5 4}$ & 239 & 298 & 537 \\
\hline $\mathbf{1 9 5 5}$ & 235 & 355 & 590 \\
\hline $\mathbf{1 9 5 6}$ & 230 & 324 & 554 \\
\hline TOTAL & 704 & 977 & 1.681 \\
\hline
\end{tabular}

Fonte: dados obtidos do Livro de Entrada do HAB, de 1954, 1955 e 1956.

Atentemos, em um primeiro momento, para o perfil feminino. Das mulheres internadas em 1954, 49\% eram classificadas como "analfabetas" (Quadro 3) e 95\% como "domésticas" (Quadro 4)..$^{40}$ Nos anos subsequentes - 1955 e 1956 - também a maioria das mulheres que

\footnotetext{
${ }^{38}$ CARRION, Carla. Desalinhados... Op. cit.

${ }^{39}$ Nos anos subsequentes, as internações foram maiores, sendo que em 1968 o hospital chegou a internar 1.711 pacientes.

40 O termo "doméstica" é bastante polissêmico em diversos momentos da história do Brasil. No caso do período estudado neste artigo, tal conceito compreende não só as trabalhadoras remuneradas que executavam serviços cotidianos dos lares alheios- tais como: lavar roupas, cozinhar, limpar a casa-, como também se referia às mulheres que ficavam em suas casas realizando as tarefas que seus lares demandavam. De acordo com Marco Antônio Gonçalves, a palavra doméstica é comumente usada na cultura brasileira em diferentes sentidos. A partir dessa constatação, o sociólogo tenta traçar alguns possíveis entendimentos para o termo. O primeiro significado elencado pelo autor nos remete a uma pessoa ligada à casa ou à família, o que pode "explicitar que alguém é criado no espaço doméstico,
} 
entrou nesse manicômio era composta por "analfabetas" e "domésticas", ou seja, em 1955, $48 \%$ eram "analfabetas" e 88\% eram "domésticas" e em 1956, 54\% das alienadas eram "analfabetas" e 75\% "domésticas".

Em relação à cor das internas, ${ }^{41}$ constata-se que estas eram em sua maioria "pardas", conforme se pode observar no Quadro 2:

Quadro 2 - Classificação por cor das mulheres internadas no hospital

\begin{tabular}{|l|c|c|c|c|}
\hline \multicolumn{1}{|c|}{ Cor } & $\mathbf{1 9 5 4}$ & $\mathbf{1 9 5 5}$ & $\mathbf{1 9 5 6}$ & Total \\
\hline Branca & 62 & 87 & 99 & 248 \\
\hline Parda & 97 & 114 & 100 & 311 \\
\hline Preta & 24 & 25 & 20 & 69 \\
\hline Ignorada & 56 & 11 & 8 & 75 \\
\hline
\end{tabular}

Fonte: dados obtidos do Livro de Entrada do HAB, de 1954, 1955 e 1956.

Quadro 3 - Índices de escolaridade entre as mulheres internadas no hospital

\begin{tabular}{|l|c|c|c|c|}
\hline Escolaridade & $\mathbf{1 9 5 4}$ & $\mathbf{1 9 5 5}$ & $\mathbf{1 9 5 6}$ & Total \\
\hline Primária & 27 & 40 & 70 & 137 \\
\hline Rudimentar & 55 & 56 & 3 & 111 \\
\hline Regular & 1 & 1 & 2 & 4 \\
\hline Superior & 2 & 1 & 1 & 4 \\
\hline Secundário & 1 & 1 & 0 & 2 \\
\hline Analfabeta & 81 & 95 & 91 & 267 \\
\hline Ignoradas & 72 & 40 & 61 & 173 \\
\hline
\end{tabular}

Fonte: dados obtidos do Livro de Entrada do HAB, de 1954, 1955 e 1956.

adotado naquele espaço, pertencente, de algum modo, à família."Outro viés da palavra doméstica diz respeito àquele ou àquela que cuida dos afazeres do lar, podendo ser remunerado ou não pelo trabalho. Por fim, Gonçalves destaca que a maior ambiguidade se encontra no fato de que doméstica pode ser a dona de casa em seu lar ou uma mulher empregada para o serviço de um grupo familiar. Essa última relação descrita gera muitos desdobramentos sociológicos e históricos, pois "este ser e não ser da família, inclusão e exclusão, o afeto e a ordem" geram dilemas e contradições no complexo cotidiano da profissão doméstica. GONÇALVES, Marco Antônio. Doméstica: uma etnografia indiscreta. Revista de Sociologia \& Antropologia, Rio de Janeiro, v. 5, n. 2, 599-607, ago. 2015.

${ }_{41} \mathrm{O}$ Instituto Brasileiro de Geografia e Estatística aponta que na década de 1950 havia mais de $60 \%$ de brancos na população brasileira e apenas $26 \%$ de pardos, algo que é bastante revelador do perfil racial (majoritariamente pardo) dos primeiros internos no Hospital Adauto Botelho. Dados disponíveis em: http://seriesestatisticas.ibge.gov.br/series.aspx?vcodigo=POP106\&sv=32\&t=populacao-presente-eresidente-por-cor-ou-raca-dados-do-universo-e-dados-da-amostra. Acesso em: 30 set. 2018. 
Quadro 4 - As profissões das mulheres internadas no hospital

\begin{tabular}{|l|c|c|c|c|}
\hline \multicolumn{1}{|c|}{ Profissão } & $\mathbf{1 9 5 4}$ & $\mathbf{1 9 5 5}$ & $\mathbf{1 9 5 6}$ & Total \\
\hline Doméstica & 160 & 186 & 154 & 500 \\
\hline Costureira & 1 & 4 & 3 & 8 \\
\hline Estudante & 2 & 8 & 1 & 11 \\
\hline Lavradora & 0 & 1 & 28 & 29 \\
\hline Menor & 3 & 6 & 0 & 9 \\
\hline Outras & 3 & 7 & 20 & 30 \\
\hline Ignoradas & 70 & 26 & 22 & 118 \\
\hline
\end{tabular}

Fonte: Dados obtidos por meio da análise do Livro de Entrada do Hospital Adauto Botelho (HAB) referentes aos anos de 1954, 1955 e 1956.

No que diz respeito ao perfil masculino, por sua vez, uma análise dos prontuários ${ }^{42}$ dos homens internados nos primeiros anos do hospital revela informações não muito distintas do constatado em relação à situação das mulheres:

Quadro 5 - As profissões dos homens internados no hospital

\begin{tabular}{|l|c|}
\hline \multicolumn{1}{|c|}{ Profissão } & Homens \\
\hline Lavrador & 11 \\
\hline Braçal & 5 \\
\hline Sem informação & 7 \\
\hline Outras profissões & 8 \\
\hline
\end{tabular}

Fonte: Documentos microfilmados - Filmes 0002 e $0004 .{ }^{43}$

\footnotetext{
${ }^{42}$ Esses dados foram obtidos a partir da pesquisa de Carla Carrion, Lilian Margotto e Elizabeth Aragão. Segundo as pesquisadoras, foram analisados 122 prontuários, sendo 81 de pessoas do sexo feminino e 41 de pessoas do sexo masculino. Cada prontuário contava com uma ou várias folhas de identificação do paciente - dependendo do número de internações. Ademais, boa parte desses prontuários são de pacientes que foram internados pela primeira vez em 1954, mas, ou a internação se estendeu até 1990 ou ocorreram sucessivas internações e altas ao longo dos anos. CARRION, Carla Torres Pereira; MARGOTTO, Lilian Rose; ARAGÃO, Elizabeth Maria Andrade. As causas das internações no Hospital Adauto Botelho (Cariacica, ES) na segunda metade do século XX. História, Ciências, Saúde - Manguinhos (Impresso), v. 21, n. 4, 1323-1340, oct./dec. 2014, p. 1326.

${ }^{43} \mathrm{O}$ artigo de onde foi extraído tal quadro não informa o ano preciso dessas informações, apenas indica a segunda metade do século XX. Cf.: Espírito Santo, 1997 apud CARRION, Carla Torres Pereira; MARGOTTO, Lilian Rose; ARAGÃO, Elizabeth Maria Andrade. As causas das internações... Op. cit., p. 1327.
} 
Quadro 6 - A instrução dos homens internados no hospital

\begin{tabular}{|l|c|}
\hline \multicolumn{1}{|c|}{ Instrução } & Homens \\
\hline Analfabetos & 10 \\
\hline Primário & 8 \\
\hline Rudimentar & 7 \\
\hline Secundário & 1 \\
\hline Sem informação & 5 \\
\hline
\end{tabular}

Fonte: Documentos microfilmados - Filmes 0002 e 0004, dados referentes à segunda metade do século $\mathrm{XX} \cdot{ }^{44}$

"Lavradores" e "trabalhadores braçais", "analfabetos" ou de formação escolar "rudimentar". Essa era o perfil dos primeiros internos do Hospital Colônia Adauto Botelho à época de sua inauguração em 1954. Cruzando as informações contidas no livro de entrada e nos prontuários em questão, é possível traçar o seguinte perfil geral dos internos no hospital naquele momento: pessoas "negras" ou "pardas", com baixo (ou nenhum) nível de escolarização, provenientes das camadas mais populares da população capixaba.

Teria, portanto, havido uma mudança considerável em relação ao perfil daqueles indivíduos outrora internados no Hospital do Psicopata ou mesmo no antigo Asilo Deus, Cristo e Caridade?

A ausência de fontes ou de dados estatísticos mais precisos a este respeito infelizmente não nos permite traçar um paralelo entre o perfil dos principais alvos das internações em hospitais e hospícios capixabas entre a primeira e a segunda metade do século XX.

De todo modo, conforme revelado em pesquisa recente sobre o tema, é possível atestar a presença de ao menos um forte elemento de continuidade no que diz respeito à prática dos internamentos em território capixaba até os anos 1950: o papel proeminente que as forças policiais continuaram e possuir nesse processo. ${ }^{45}$

De acordo com os dados recolhidos por Carla Carrion, Lilian Margotto e Elizabeth Aragão, os prontuários de antigos pacientes do Hospital Colônia Adauto Botelho revelam que parte considerável dos indivíduos ali internados havia sido encaminhada à instituição pela Chefatura de Polícia da capital:

"Procedência: Hospital do Psicopata" - contam alguns prontuários. "Procedência: Chefatura de Polícia" - contam outros. E um dado não necessariamente anula o

\footnotetext{
${ }^{44}$ ARAGÃO, Elizabeth Maria Andrade. As causas das internações... Op. cit.

${ }^{45}$ CARRION, Carla Torres Pereira; MARGOTTO, Lilian Rose; ARAGÃO, Elizabeth Maria Andrade. As causas das internações... Op. cit., p. 1329.
} 
outro: há aqueles que, pela polícia, foram levados ao Hospital do Psicopata e, mais tarde, encaminhados para o recém-inaugurado Hospital Adauto Botelho. Como se este último representasse uma continuidade - mais moderna e duradoura - do outro. Ser encaminhado de um hospital para outro fala, então, da durabilidade de algumas internações: um processo contínuo, do qual parecia não haver saída. ${ }^{46}$

Esse papel de destaque das forças policiais na construção de uma espécie de público alvo para o novo hospital se confirma a partir das entrevistas concedidas por antigos funcionários da instituição às pesquisadoras em questão. Segundo uma das entrevistadas: "Se você fizesse um ato na rua, onde você vinha parar? No Adauto Botelho. Algum ato que a polícia talvez não gostasse, abordasse, qualquer coisa assim. Até mesmo você estar despido na rua. Então o ato de internação era muito pela polícia, era difícil a família estar internando. Era a polícia." ${ }^{\prime 47}$

Na prática, na maior parte das vezes, a classe, a cor e a situação de vulnerabilidade social falavam mais alto do que a própria doença mental no que dizia respeito aos critérios estabelecidos pela polícia para a efetivação dos internamentos no hospital. Exemplar nesse sentido é o caso da jovem Vera (nome fictício), internada no Adauto Botelho em março de 1955:

No juizado de menores, a examinanda foi trazida a este nosocômio. Declara ainda a examinanda que os progenitores vivem em perfeita harmonia, o mesmo acontecendo com os irmãos. [...] A paciente apresenta-se ao exame calma, colaboradora e lúcida. Auto-orientada. Orientada alo-psiquicamente e quanto a situação. ${ }^{48}$ No decorrer da anamnese, não se nota nenhum sinal de desequilíbrio mental. A paciente apresenta-se ao exame calma e colaboradora e lúcida. Autoorientada, alo-psiquicamente e quanto a situação, Extrovertida e eufórica. Diagnóstico: não apresenta perturbação mental. ${ }^{49}$

Neste caso, o histórico familiar e a origem social se mostravam como elementos mais importantes do que a saúde mental da paciente enquanto justificativa para a sua internação.

Os casos específicos em questão, os dados estatísticos gerais, bem como o itinerário histórico acima estabelecido apontam, portanto, para o que acreditamos ser a comprovação da hipótese inicial sustentada no presente artigo: a modernização da medicina no Espírito Santo não foi capaz de romper com antigas práticas, mantendo a lógica repressiva e excludente que caracterizou o trato com a loucura em nosso estado ao menos desde o século XIX.

Em outras palavras, o surgimento do Hospital Colônia Adauto Botelho pode ser pensado como um claro exemplo de segregação social que demarcava o espaço e o tratamento dispensado entre os civilizados e os que não se enquadravam no novo modelo de cidade que se propunha para o Espírito Santo e para o Brasil na segunda metade do século XX.

\footnotetext{
${ }^{46}$ Entrevista com Maria apud CARRION, Carla Torres Pereira; MARGOTTO, Lilian Rose; ARAGÃO, Elizabeth Maria Andrade. As causas das internações... Op. cit.

47 Ibidem, p. 1330.

48 O termo "auto-orientada" diz respeito à capacidade de a paciente reconhecer seus dados pessoais, saber se identificar; "Orientada alo-psiquicamente" quer dizer que a paciente tem noções temporais, espaciais e sabe informar sobre alterações no seu corpo, como por exemplo localizar o nariz, saber sobre uma paralisia, uma amputação.

${ }^{49}$ RELATÓRIO de enfermagem, n. 663. Promemória (arquivo), 23 mar. 1955.
} 


\section{Conclusão}

A trajetória de parte da história da loucura no Espírito Santo apresenta dois momentos cruciais, sendo o primeiro assentado sob a ideia de que havia uma lacuna devido à falta de um espaço apropriado para receber os alienados e o segundo, descrito como a efetiva realização de um horizonte de expectativa pautado na consolidação dos ideais progressistas e civilizados. Dessa maneira, a versão apresentada pelo estado e por veículos de comunicação local tratavam de reforçar a narrativa que referenciava a construção do Hospital Colônia Adauto Botelho como um ponto de inflexão para o campo da saúde mental capixaba.

Entretanto, quando recorremos a fontes alternativas, como entrevistas de funcionários da instituição hospitalar, livros de entrada e prontuários, percebemos que é possível falar muito mais em continuidades do que em rupturas em relação às antigas práticas policialescas de entendimento do problema da loucura no estado.

O nosocômio em questão tratou de concentrar uma demanda própria da cidade em tempos anteriores, isto é, de retirada dos espaços públicos dos tipos indesejáveis - negros ou pardos, pobres e com baixo (ou nenhum) nível de escolarização - e que não contribuíam ao projeto modernizador da cidade e da nação. As práticas repressivas e degradantes do Hospital Colônia Adauto Botelho ganharam um verniz de modernidade que não acompanhava seu discurso humanista, se encontrando em descompasso com a representação estabelecida sobre si.

Nesse sentido, tentou-se implementar em terras capixabas na década de 1950 uma espécie de modernização das práticas médicas que, todavia, tendeu à manutenção da lógica excludente anterior, visto que ela continuou a ser utilizada como mecanismo de controle e de exceção.

Este era, portanto, um tipo de modernização dos saberes e dos costumes que operou em consonância com a crítica foucaultiana dos jogos de exclusão e do aprisionamento da loucura num mundo moral com o advento da modernidade no ocidente. ${ }^{50}$ Compreender as especificidades do caso capixaba - instigando a realização de outras investigações sobre o tema -, à luz da lógica foucaltiana em questão foi o objetivo principal do presente trabalho.

${ }^{50}$ FOUCAULT, Michel. A História da Loucura... Op. cit., p. 546-547. 